Bull. Mater. Sci., Vol. 6, No. 2, May 1984, pp. 339-367. (C) Printed in India.

\title{
Radiation effects in nuclear reactor materials-Correlation with structure
}

\author{
P RODRIGUEZ, R KRISHNAN * and C V SUNDARAM \\ Reactor Research Centre, Kalpakkam 603 102, India \\ - Metallurgy Division, Bhabha Atomic Research Centre, Trombay, Bombay 400085, India
}

\begin{abstract}
A review of radiation effects in nuclear reactor materials has been made; the irradiation effects have been correlated with the crystal structure of the materials. Five phenomena, irradiation hardening, irradiation embrittlement, irradiation creep, irradiation growth and void swelling that occur in materials by neutron irradiation in a reactor environment have been discussed with a view to explaining the physics of the phenomena and the engineering consequences. Metallurgical approaches for improving the irradiation performance of materials and for developing new alloys with better resistance to radiation damage have been pointed out.
\end{abstract}

Keywords. Nuclear reactor materials; irradiation effects; radiation damage; irradiation hardening; irradiation embrittlement; helium embrittlement; irradiation creep; irradiation growth; void swelling; stainless steels; zirconium alloys; uranium; nickel alloys.

\section{Introduction}

The subject of radiation effects in materials is a vital area of relevance to reactor engineering as well as a large field for basic materials research. In this paper we shall discuss neutron irradiation effects in a nuclear reactor environment in structural materials. Two effects are known to occur in non-fissile materials in the intense neutron environment of a nuclear reactor. One is the extensive displacements of the atoms from their lattice sites due to elasic interactions with the impinging neutrons. The second is the formation of impurity atoms in the materials by transmutation reactions. Both these effects, the displacement of atoms from their lattice sites and the consequent production of various types of defect structures as well as the production of impurity atoms due to transmutation reactions can influence important macroscopic properties like strength, ductility and dimensional stability which are the most important features for the practical application of the structural materials. The changes brought about by irradiation on these properties are quite often unfavourable and adverse, justifying the influence of radiation on inaterials being referred to as "radiation damage". In this paper five phenomena, irradiation hardening, irradiation embrittlement, irradiation creep, irradiation growth and void swelling that occur in materials due to neutron irradiation in a reactor environment will be discussed. We will also attempt to correlate the irradiation effects with the crystal structure of the various materials.

\section{Irradiation hardening}

The general effects of neutron irradiation on the mechanical behaviour are (i) an increase in the yield strength (irradiation hardening); (ii) an increase in the ultimate 


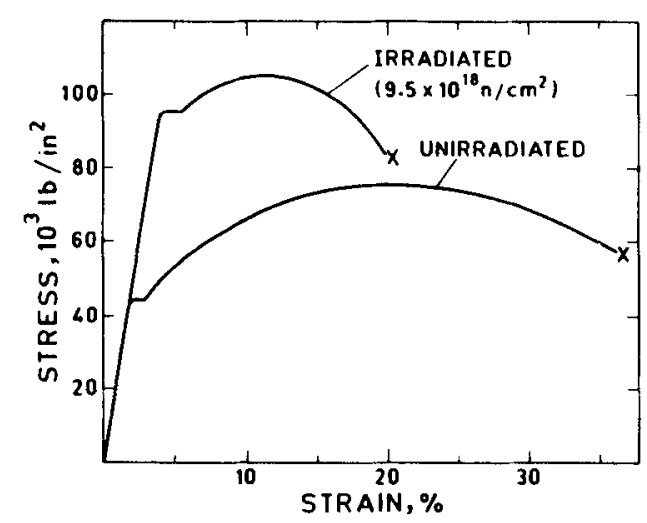

Figure 1. Change in roomtemperature tensile properties of mild steel produced by neutron irradiation (Little 1976).

tensile strength which is less strong than the increase in the yield strength; (iii) a decrease in the rate of work hardening and (iv) a reduction in the uniform and total elongations. These effects are illustrated in the typical example for mild steel (Little 1976) given in figure 1.

The strengthening or irradiation hardening is caused by microstructural defects introduced by irradiation. In pure metals, the impediment to dislocation motion must originate directly from radiation-induced lattice defects whereas in alloys, indirect effects like radiation-induced precipitation are also possible. The defects introduced by irradiation can vary from single vacancies and interstitials of one atom diameter size to voids and helium bubbles as large as 3 to $30 \mathrm{~nm}$ in diameter or higher. The primary defects generated are point defects (interstitials and vacancies). At low temperatures, where the mobilities of these defects are limited they combine to form multiple point defects, for example di-vacancies, tri-vacancies etc., or clusters of point defects or complexes with solutes which are a few atom diameter in size. As the irradiation temperature increases, planar defects like the depleted zones which can even collapse into planar vacancy clusters and vacancy loops form. At temperatures between 0.1 to $0.3 T_{m}\left(T_{m}\right.$ is the melting point in $\left.\mathrm{K}\right)$ the interstitials are mobile and they can annihilate by combining with immobile vacancies; annealing of interstitials at vacancy loops and other sinks also occur. Interstitials also agglomerate to form clusters of interstitials. At still higher temperatures between 0.3 and $0.5 T_{m}$, the vacancies also become mobile which cause their annihilation by recombination with interstitials; annealing of both interstitials and vacancies at various sinks like loops, dislocations etc also take place, the interstitial clusters further agglomerate to form interstitial type dislocation loops while an excess concentration of vacancies is produced which coalesce to form voids. Around and above $0.5 T_{m}$ volume diffusion becomes possible and if helium has been released as a transmutation product helium bubbles form. A list of the various defect structures (with their sizes) that can be produced in materials at different irradiation temperatures are given in table 1.

There have been two approaches to explain irradiation hardening (Diehl 1970). In earlier attempts, irradiation hardening was considered to be source hardening (that is enhancement of the stresses necessary to activate dislocation sources which are considered to be pinned by the irradiation-produced defects attached to them). A second approach has been the dispersed barrier hardening approach which considers impediment of dislocation motion in irradiated materials by localised obstacles 
Table 1. Defects produced by irradiation

\begin{tabular}{|c|c|c|}
\hline $\begin{array}{c}\text { Temperature } \\
T / T_{m}\end{array}$ & Defect & Size \\
\hline \multicolumn{3}{|l|}{0} \\
\hline \multirow{3}{*}{$\begin{array}{l}\vee \\
0.1\end{array}$} & $\begin{array}{l}\text { Point defects: } \\
\text { Vacancies and interstitials }\end{array}$ & $\begin{array}{l}\text { One atomic } \\
\text { diameter }\end{array}$ \\
\hline & $\left.\begin{array}{l}\text { Multiple point defects } \\
\text { Clusters of point defects } \\
\text { Complexes of vacancies and } \\
\text { interstitials with solutes }\end{array}\right\}$ & $\begin{array}{l}\text { a few atomic } \\
\text { diameter }\end{array}$ \\
\hline & Vacancy clusters and loops & diameter $<7 \mathrm{~nm}$ \\
\hline & Interstitial loops & diameter $>7 \mathrm{~nm}$ \\
\hline & $\begin{array}{l}\text { Rafts (agglomerates of } \\
\text { clusters and small loops) }\end{array}$ & $\begin{array}{l}6-10 \mathrm{~nm} \text { thick, } \\
100-200 \mathrm{~nm} \text { in } \\
\text { length and width }\end{array}$ \\
\hline \multirow{3}{*}{$\underset{0.5}{V}$} & Voids & $10-60 \mathrm{~nm}$ \\
\hline & Helium bubbles & $3-30 \mathrm{~nm}$ \\
\hline & $\begin{array}{l}\text { Transmutation atoms } \\
\text { (produced at all temperatures } \\
\text { but agglomerates at } \\
T / T_{m}>0.5 \text { ) }\end{array}$ & \\
\hline
\end{tabular}

randomly distributed in the lattice. The latter approach based on the theory of thermally activated dislocation motion has gained considerable experimental and theoretical support particularly in view of the fact that the approach has been extensively proved to be valid in unirradiated materials also.

The basis of the theory of thermally activated deformation (for recent reviews, see Kocks et al 1975; Li and Mukherjee 1972; Rodriguez and Dasgupta 1972; Evans and Rawlings 1969) is that the barriers to dislocation motion may be divided into two categories, short range and long range obstacles depending on the magnitude of the distance over which the force exerted by the obstacle extends. The shear flow stress $\tau$ can thus be considered to consist of two components $\tau_{\mu}$ and $\tau^{*}$. $\tau_{\mu}$ called the athermal or internal or long range stress arises from interaction of moving dislocations with obstacles whose force extends over distances of the order of ten atomic diameters or more. (For example the forces due to dislocations on parallel slip planes, grain boundaries or large obstacles such as second phase particles). $\tau_{\mu}$ depends on temperature only through the shear modulus $\mu . \tau^{*}$ is the effective or thermal component of flow stress and arises from interaction of moving dislocations with short range obstacles like solute atoms, clusters, point defects, forest dislocations, alternate low and high energy configurations of the dislocation core (for example Peierls-Nabarro barrier and non-planar dislocations) etc. $\tau^{*}$ is influenced by both temperature and strain rate. 


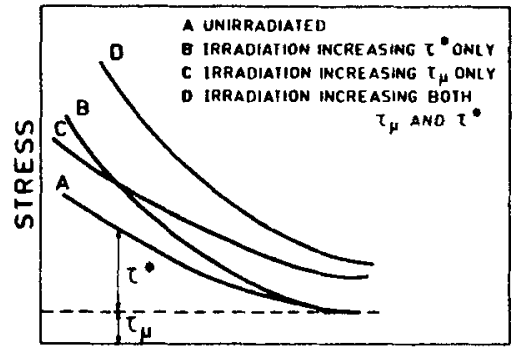

TEMPERATURE
Figure 2. Schematic illustration of possible changes in thermal and athermal components of flow stress due to irradiation (Rodriguez 1977).

The variation of flow stress with temperature and strain rate showing partitioning of the thermal and athermal stress components is shown in figure 2 (Rodriguez 1977). The various defect structures produced by irradiation (table 1) can have both long range and short range interactions with dislocations. An irradiation-induced defect can become rate-controlling when the short range energy barrier presented by it exceeds the highest barrier in the unirradiated condition and thus alters the temperature dependence of the flow stress. Schematic illustrations of possible changes in $\tau_{\mu}$ and $\tau^{*}$ by irradiation are also shown in figure 2. Curve $A$ is the flow stress vs temperature curve in the unirradiated condition. Curve $B$ is obtained when irradiation increases only the thermal component of flow stress. When irradiation hardening is purely athermal in nature, the flow stress $v$ s temperature curve is just shifted up along the stress axis, resulting in curve $C$. Curve $D$ represents the situation when irradiation increases both the components of flow stress. Most of the experimental results rule out situation $\mathbf{B}$, consistent with the fact that most of the defects introduced by irradiation have both

Table 2. Summary of results of dislocation dynamics in irradiated materials (Rodriguez 1977)

\begin{tabular}{|c|c|c|}
\hline \multirow[t]{2}{*}{ Lattice type } & \multicolumn{2}{|c|}{ Rate-controlling obstacle } \\
\hline & $\begin{array}{l}\text { Un-irradiated } \\
\text { (Rodriguez and } \\
\text { Dasgupta 1972) }\end{array}$ & Irradiated \\
\hline BCC & $\begin{array}{l}\text { P-N barrier } \\
\text { Interstitial } \\
\text { solutes }\end{array}$ & $\begin{array}{l}\text { P-N barrier } \\
\text { Solutes } \\
\text { Solute-defect complexes } \\
\text { Clusters or loops } \\
\text { Divacancies } \\
\text { (Little 1976; } \\
\text { Arsenault 1976) }\end{array}$ \\
\hline $\begin{array}{l}\text { FCC and } \\
H C P, c / a>\text { ideal } \\
\text { (basal slip) }\end{array}$ & $\begin{array}{l}\text { Intersection of } \\
\text { forest dislocations }\end{array}$ & $\begin{array}{l}\text { Depleted zones (Diehl 1970) } \\
\text { Faulted loops (Koppenal } \\
\text { and Arsenault 1971) }\end{array}$ \\
\hline \multirow[t]{2}{*}{$\begin{array}{l}\text { HCP } c / a<\text { ideal } \\
\text { (prism slip) }\end{array}$} & $\begin{array}{l}\text { Interstitial } \\
\text { solutes }\end{array}$ & $\begin{array}{l}\text { Interstitial solutes } \\
\text { (Hamad et al 1975) }\end{array}$ \\
\hline & P-N barrier & $\begin{array}{l}\text { Irradiation-induced } \\
\text { defects (Kayano et al 1977) }\end{array}$ \\
\hline
\end{tabular}


long range and short range interactions with dislocations and hence the athermal component of flow stress will invariably be increased by irradiation irrespective of whether the rate-controlling mechanism is altered (D) or not (C).

A critical summary of the results indicating that the effects mainly depend on the crystal structure and the operative slip system is given in table 2 (Rodriguez 1977). Excellent reviews giving details of the results are available for FCC metals (Diehl 1970; Koppenal and Arsenault 1971) and BCC metals and alloys (Little 1976 Arsenault 1976). Experimental studies on HCP materials on the other hand have been very few (Hamad et al 1975 and Kayano et al 1977).

\subsection{BCC metals}

Figure 3 (Little 1976) is illustrative of the conflicting results obtained in parallel investigations on BCC metals. Figure 3a giving results on polycrystalline $\alpha$-iron is typical of data (Ohr et al 1968) showing that irradiation produces no detectable change in the temperature dependence of yield or flow stress, but gives rise to temperature-insensitive radiation hardening. Data demonstrating other results that reveal an increase in the temperature dependence is exemplified by the results for single crystal $\alpha$-iron of two purities, irradiated to a range of neutron doses shown in figure $3 \mathrm{~b}$ (Diehl et al 1968). The above two observations refer principally to tests performed below room temperature. A third set of results on an aluminium-grain-size-controlled mild steel (Little 1967), in which the test temperature range was extended up to $523 \mathrm{~K}$ demonstrates that the radiation hardening is temperature-dependent above room temperature but temperature insensitive below (figure 3c). Since the strong temperature dependence of the

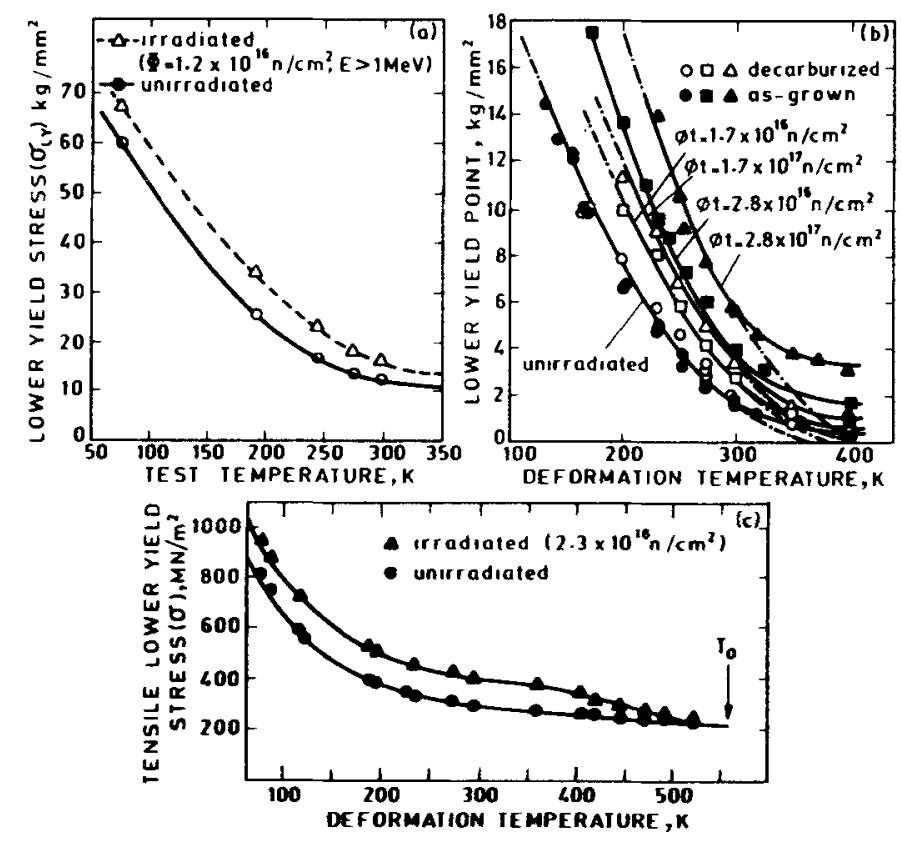

Figre 3. Conflicting results obtained in paralled investigations on BCC metals (Little 1976), (a) polycrystalline $\alpha$-Fe (Ohr et al 1968); (b) $\alpha$-Fe single crystals (Diehl et al 1968) (c) aluminium grain size controlled stoel (Little 1967). 
unirradiated yield stress also ceases at about room temperature, Little (1967) inferred that thermally-activated overcoming of radiation-produced defects occur only at temperatures above which the unirradiated rate-controlling mechanism becomes athermal; in the absence of the latter, the defects introduced by irradiation would have been rate-controlling even at lower temperatures.

Seidel (1969) has explained the differences in the observations on irradiation effects in polycrystals and single crystals of $\alpha$-iron (figures $3 a$ and $b$ ) as arising from the opposing influences of irradiation on the two parameters $\sigma_{i}$ and $K$ in the well-known Hall-Petch relationship $\sigma=\sigma_{i}+K d^{-1 / 2}$ relating strength $\sigma$ to grain diameter $d$. In the unirradiated condition, the temperature dependence of flow stress is mainly contained in the Hall-Petch intercept $\sigma_{i}$. Since irradiation is found to increase the temperature dependence of the single crystal flow stress (figure $3 \mathrm{~b}$ ) it is to be inferred that the temperature dependence of $\sigma_{i}$ is increased by irradiation. The absence of any change in the temperature dependence of the polycrystal flow stress therefore indicates that irradiation has an opposing influence on the Hall-Petch slope $K$, and particularly its variation with temperature. Diehl and Seidel (1969) has cited in support of the above explanation, the results of Chow et al (1969) indicating a decrease in $K$ with temperature after irradiation which nullifies the increase in the temperature dependence of $\sigma_{i}$ such that the temperature dependence of the overall flow stress remains unaffected.

Before closing the discussion on BCC metals, two important facts should be pointed out. One is the existing controversy regarding the rate-controlling obstacle in the BCC metals in the unirradiated condition itself (Rodriguez and Dasgupta 1972; Kocks et al 1975; Li and Mukherji 1972; Evans and Rawlings 1969; Arsenault 1976); whether it is the Peierls-Nabarro barrier or the interstitial solutes? The second is the effect of interstitial solute content on the change in $\tau^{*}$ due to neutron irradiation (Little 1976; Arsenault 1976). Closely associated with the latter are the phenomena of radiation anneal hardening (Little 1976; Wechsler 1972; Arsenault 1973) and radiation softening (Arsenault 1973, 1976), which are also influenced by the interstitial solute content. These effects are a consequence of the irradiation damage (vacancies, interstitials, divacancies, diinterstitials and clusters) acting as trapping sites or sinks for interstitial solutes and vice versa.

\subsection{FCC metals}

Compared to BCC metals, the agreement among the experimental results on FCC metals is much better (Diehl 1970; Koppenal and Arsenault 1971). The temperature dependence of flow stress is increased by irradiation and the intersection of forest dislocations is replaced by irradiation-produced defects as the rate-controlling obstacle. While there is agreement in the experimental results, the interpretation of results has not been free from controversies. One disagreement is regarding the nature of the interaction of the rate-controlling defects with dislocations. Koppenal (1965) and Koppenal and Arsenault $(1965,1971)$ have concluded that the rate-controlling obstacle is faulted loops and that the results conform to the model of Fleischer (1962) of strengthening by the tetragonal distortion around defects. On the other hand, it has also been claimed (Diehl 1970; Diehl and Seidel 1969), that the results are in better agreement with the model of Seeger (1958) of dislocations cutting through a forest of dispersed barriers (depleted zones) if it is assumed that an obstacle size spectrum exists 
and therefore a unique temperature-independent activation energy does not exist. Another point of disagreement between the two groups has been on the contributions of irradiation hardening to the thermal and athermal components of flow stress. The results on FCC metals correspond to curve D of figure 3 which as discussed earlier should be interpreted as increases in both the thermal and athermal components of flow stress on irradiation. Arsenault and Koppenal have adopted this view and the analysis of results was accordingly made. Diehl and coworkers, on the other hand, have assumed that $\tau_{\mu}$ is unaffected by irradiation and therefore the difference between the irradiated flow stress and the $\tau_{\mu}$ for the unirradiated condition was taken as the thermal component of flow stress for the irradiated state.

\subsection{HCP metals}

Studies of dislocation dynamics in irradiated HCP metals have been very few. Hamad et al (1975) in a systematic study of quench-hardening and neutron-irradiation hardening in zirconium have concluded that the defects produced by quenching or irradiation lead to only athermal hardening; the rate-controlling obstacle, which is the interstitial solutes, remains unaltered by irradiation. More recent work by Matta et al (1977) has confirmed these findings.

Kayano et al (1977), on the other hand, found that in titanium, another HCP metal similar to zirconium in its deformation characteristics, the thermal activation parameters of deformation were altered by irradiation. Irradiation-produced defects, too small to be observed by electron microscopy, were considered to be related to the thermal component of stress.

\section{Irradiation embrittlement}

The primary issues in mechanical metallurgy are of course strength and ductility. It is now well established that all factors or treatments that strengthen metals also cause a decrease in ductility (the effect of grain size is the only known exception). It comes as no surprise therefore, that radiation hardening is almost always accompanied by a decrease in ductility though the enhanced fracture susceptibility caused by irradiation is probably the most severe and most dramatic of all the hardening mechanisms. The reduction in ductility measured by the decrease in the uniform or total elongation in a tensile test or in the fracture toughness evaluated from impact tests or fracture mechanics tests or even as the area under the stress-strain curve is referred to as irradiation embrittlement. Four types of irradiation embrittlement have been identified: (i) radiation embrittlement in BCC metals and alloys that undergo a ductile-brittle transition; (ii) radiation embrittlement in normally ductile metals like FCC metals; (iii) high temperature grain boundary embrittlement arising from the formation of helium bubbles from $(n, \alpha)$ reactions and (iv) embrittlement due to the formation of other transmutation products.

\subsection{Irradiation embrittlement in BCC metals and alloys}

BCC metals and alloys undergo a transition in fracture mode from ductile behaviour to brittle fracture as the temperature is decreased; below the transition temperature called 
the nil ductility transition temperature (NDTT), fracture occurs by cleavage and the energy required for fracturing a specimen in an impact test is negligible.

Irradiation has two effects on BCC metals and alloys, firstly it increases the NDTT and secondly it brings down the fracture energy of the material even in the ductile region (so-called upper shelf energy). Irradiation embrittlement and the increase in NDTT are serious engineering problems in nuclear reactors since the materials chosen for pressure vessels and containment vessels of reactor systems are made of ferritic steels which have BCC crystal structure and undergo the ductile to brittle transition. By code requirements, the operation of the reactor is permissible only if the NDTT of the component material is atleast $\sim 37^{\circ} \mathrm{C}$ below the operating temperature of the component.

The influence of neutron irradiation on the NDTT of ASTM A203 Grade D steel (a low alloy ferritic steel containing approximately $\sim 3.5 \%$ nickel) is shown in figure 4 (Baldev Raj et al 1983). The results have been obtained from charpy-V half size specimens of the steel. Using the criterion of $30 \mathrm{~J}$ energy to determine the NDTT, in the unirradiated condition (curve A) the steel has NDTT of $-91^{\circ} \mathrm{C}$ and an upper shelf energy of about $100 \mathrm{~J}$. Irradiation to a fluence level of $3.5 \times 10^{19} \mathrm{n.cm} \mathrm{cm}^{-2}$ (curve B) increases the NDTT to around $150^{\circ} \mathrm{C}$ while bringing down the upper shelf energy to as low as $40 \mathrm{~J}$. At a lower fluence of $5 \times 10^{18} \mathrm{n} . \mathrm{cm}^{-2}$ (curve C) the NDTT is shifted to only about $-10^{\circ} \mathrm{C}$ and the upper shelf energy is about $50 \mathrm{~J}$. The curve $\mathrm{D}$ shows the impact energy transition curve for the material that has been annealed at $300^{\circ} \mathrm{C}$ for 15 days following irradiation to a fluence level of $3.5 \times 10^{19} \mathrm{n.cm}{ }^{-2}$. That is it shows the recovery in properties that can be obtained, by annealing at higher temperatures in specimens that have been irradiated to a brittle condition corresponding to curve B. It is seen that the NDTT has been brought down to $-10^{\circ} \mathrm{C}$ and the upper shelf energy has increased to about $80 \mathrm{~J}$. This effect of annealing at higher temperatures offers the possibility of using in situ annealing of reactor components to remove at least a portion of the irradiation damage and to reduce the NDTT to acceptable levels in those cases where the shift has become excessive (Mansur and Bloom 1982; Steele 1975; Spitznagel et al 1976).

The ductile brittle transition in BCC metals is associated with the strong temperature dependence of the yield strength in these materials which has already been discussed in \$2.1. According to the Ludwig-Davidenkov criterion (Grant and Fortner 1972; Wechsler 1976) for the NDTT illustrated in figure 5, the ductile-to-brittle transition

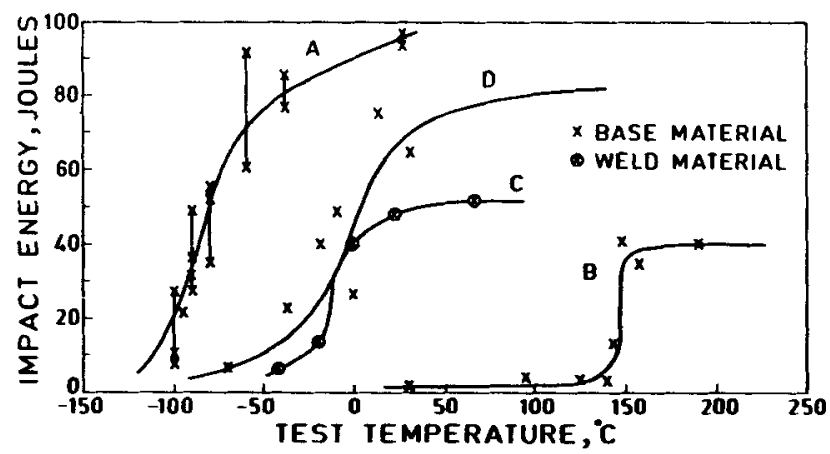

Figure 4. Impact energy vs temperature curves for ASTM A 203 grade D steel (Baldev Raj et al 1983); $A=$ Unirradiated; $B=$ Irradiated to a fluence of $3.5 \times 10^{19} \mathrm{ncm}^{-2} ; C=$ Irradiated to a fluence of $5 \times 10^{18} \mathrm{ncm}^{-2} ; \mathrm{D}=$ Annealed at $300^{\circ} \mathrm{C}$ for 15 days after irradiation to a fluence of $3.5 \times 10^{19} \mathrm{ncm}^{-2}$. 


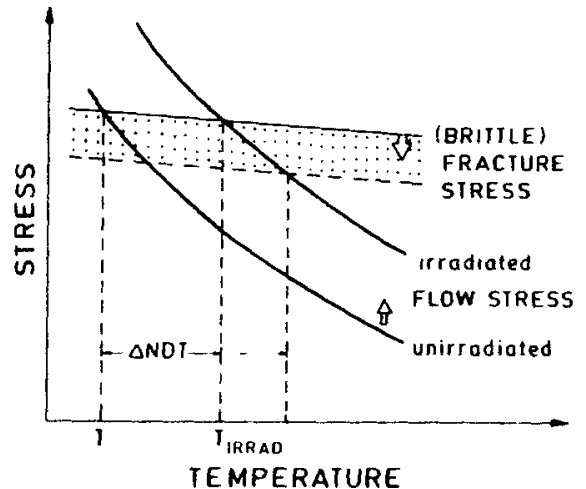

Figure 5. Schematic illustration of the Ludwik-Davidenkov criterion for NDTT and its shift with irradiation.

occurs at a temperature where the yield stress, due to its strong increase with decrease in temperature reaches the critical stress for cleavage fracture which is much less temperature-dependent. Furthermore the cleavage fracture stress is relatively independent of microstructural features such as the defect clusters introduced by irradiation. The yield stress however increases drastically upon irradiation thereby shifting the NDTT to higher values as shown in figure 5. To explain the decrease in the upper shelf energy with irradiation it has been suggested (Ehrlich 1980) that the cleavage fracture stress could be reduced by irradiation-induced defects; the dashed line in figure 5 illustrates this situation which also results in a larger shift in the NDTT.

Residual elements in ferritic steels are found to have a very significant effect on the extent of irradiation embrittlement (Bement 1972). Two elements that have the most deleterious effect are phosphorous and copper. Studies by Brenner et al (1978) using field ion microscope to determine the structure on an atomic level have shown that copper and phosphorous can stabilise a high concentration of very small microvoids $\left(8 \times 10^{21}\right.$ voids $/ \mathrm{m}^{3}$ with a mean diameter of $\left.0.6 \mathrm{~nm}\right)$. These stabilised microvoids would produce the increased flow stress and the associated shift in NDTT. Notwithstanding the influence of residual elements on radiation defect stabilisation, there are other intrinsic effects of these elements on impact behaviour which may prove to be important in the sensitivity to radiation embrittlement. Those residual elements which restrict cross-slip, cause significant matrix strengthening, and reduce surface energy are primarily suspect.

Table 3. Effects of residual elements on sensitivity to irradiation embrittlement of steel (Bement 1972)

\begin{tabular}{|c|c|c|c|c|c|c|}
\hline Element & $\begin{array}{c}\text { Increases } \\
\text { NDTT }\end{array}$ & $\begin{array}{c}\text { Reduces } \\
\text { ductile } \\
\text { shelf }\end{array}$ & $\begin{array}{c}\text { Forms } \\
\text { precipi- } \\
\text { tate }\end{array}$ & $\begin{array}{c}\text { Reduces } \\
\text { surface } \\
\text { energy }\end{array}$ & $\begin{array}{c}\text { Increases } \\
\text { flow } \\
\text { stress }\end{array}$ & $\begin{array}{c}\text { Restricts } \\
\text { cross } \\
\text { slip }\end{array}$ \\
\hline $\begin{array}{l}\mathrm{P} \\
\mathrm{Cu} \\
\mathrm{S} \\
\mathrm{V} \\
\mathrm{Al} \\
\mathrm{Si}\end{array}$ & $\begin{array}{l}\sqrt{ }(\mathbf{S}) \\
\sqrt{ }(\mathbf{S}) \\
\sqrt{(\mathbf{M})} \\
\sqrt{(\mathbf{S})} \\
\sqrt{ }(\mathbf{M})\end{array}$ & $\begin{array}{c}- \\
\sqrt{ }(\mathrm{S}) \\
\text { Increases } \\
\sqrt{ }(\mathrm{M})\end{array}$ & $\begin{array}{l}\sqrt{V} \\
\sqrt{ }(S) \\
\sqrt{ } \\
\sqrt{ }(S) \\
\sqrt{ }(S)\end{array}$ & $\begin{array}{l}\sqrt{ }(\mathbf{S}) \\
\sqrt{ } \\
\sqrt{ }(\mathbf{S})\end{array}$ & $\begin{array}{l}\sqrt{ }(\mathbf{S}) \\
\sqrt{ }(\mathbf{S}) \\
- \\
\sqrt{ } \\
\sqrt{ }\end{array}$ & $\frac{\sqrt{ }(\mathbf{S})}{\sqrt{ }}$ \\
\hline
\end{tabular}


Some of the elements that fall in this category are listed in table 3 (Bement 1972). It is seen that phosphorous contributes strongly to all the three processes, copper is a solid solution hardener and silicon, vanadium, aluminium and cobalt diminish the ease of cross-slip.

The preceding discussion on the low temperature embrittlement in BCC metals and alloys have been restricted to a few qualitative remarks aimed at explaining the physics of the phenomenon. The literature on the subject is very extensive and detailed discussions on the influence of chemical composition, metallurgical variables and irradiation variables (neutron dose, dose rate, neutron spectra and irradiation temperature) on the influence of irradiation on NDTr have been well documented in the literature (Wechsler 1967; Steele 1975; Nichols and Cowan 1971; Ehrlich 1980).

\subsection{Irradiation embrittlement in normally ductile metals and alloys}

Figure 6 shows the effect of neutron irradiation on the tensile stress-strain behaviour of a normally ductile metal like FCc copper (Makin 1967). The essential features of these effects are: (i) increase in yield strength (ii) increase in the ultimate tensile stress, but to a smaller extent than the increase in yield stress; (iii) decrease in the rate of work hardening; and (iv) decreases in the uniform and total elongations. These effects of irradiation on the shape of the tensile stress-strain curve for copper appear to be broadly representative of ductile metals of all the three crystal structures (FCC, BCC, and $\mathrm{HCP}$ ) and of pure metals and complex alloys alike. For example it may be seen that even in a material like mild steel which shows the ductile-brittle transition the effect on the stress-strain curve at room temperature at which mild steel is ductile (figure 1 ) is quite similar to the effect in face centred cubic copper.

The reductions in ductility caused by irradiation in normally ductile materials have been attributed to the phenomenon of dislocation channelling, which is widely exhibited by irradiated or quenched FCC, BCC and HCP metals (Wechsler 1976). The radiation-produced defect clusters are apparently removed when slip dislocations are set in motion along the slip plane in the earlier stages of deformation. The slip process then continues by the motion of subsequent slip dislocations along the same channel in preference to the nucleation of a new band in an adjacent region of the crystal. As a result, the deformation becomes considerably more localised than is the case for

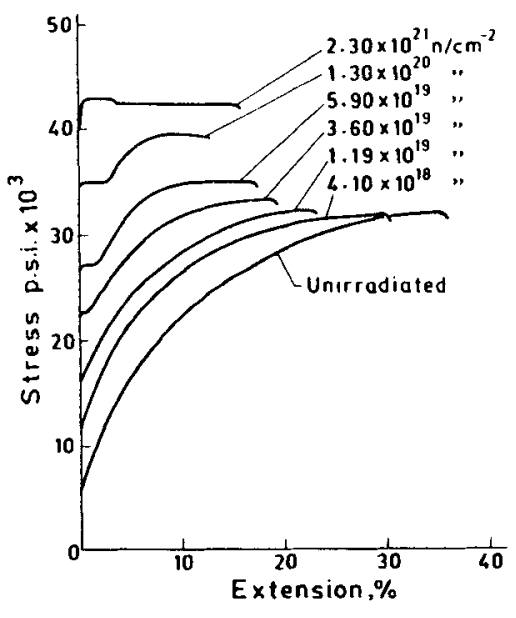

Figure 6. Stress-strain curves for polycrystalline copper tested at $20^{\circ} \mathrm{C}$ after irradiation to the doses indicated (Makin 1967). 
unirradiated metals. Due to the dislocation channelling deformation takes place in the glide bands in a catastrophic manner and leads to plastic instability localised in the channels or slip bands at a strain "averaged over the gauge length" which is smaller than for homogenous deformation. The phenomenon of dislocation channeling is also able to explain the reduction in work hardening rate due to irradiation in ductile metals. The removal of irradiation-produced obstacles by the moving dislocations will result in a reduction in the enhancement of flow stress with strain and consequently in a reduced work hardening rate. It has been pointed out (Diehl 1977) that the reduced work hardening and dislocation channeling are essentially the same phenomenon on different scales (macroscopic and microscopic). On a macroscopic scale plastic instability and necking always set in when in a tensile test, within a small strain interval, the increase in stress due to work hardening is too small to compensate the reduction in cross-section so that the applied load remains constant or even decreases. A general reduction in work hardening will always therefore result in premature necking and lower values of uniform and total elongations. On a microscopic scale the tendency of ductile materials to become less ductile after irradiation is related to the mechanisms by which defect clusters produced by irradiation are eliminated by the moving slip dislocations. The various proposed mechanisms whereby slip dislocations interact with and remove radiation-produced dislocation loops and other defects have been reviewed and summarised by Wechsler (1976).

\subsection{Helium embrittlement}

Neutronically generated helium has a strong effect on the elevated temperature fracture behaviour of metals and alloys above $0 \cdot 4 T_{m}$. At these temperatures, grain boundary sliding becomes prominent and intergranular fracture occurs by wedge cracking at grain boundary junctions or by the fracture of continuous brittle grain boundary precipitates or by cavitation. Helium produced by the various transmutation reactions in the reactor environment causes intergranular embrittlement by stabilising the cavities and the wedge cracks; the growth and coalescence of helium bubbles have also been suggested as a possible mechanism for helium embrittlement. Another suggested mechanism is that helium reduces the grain boundary energy relative to the matrix simultaneously strengthening the matrix relative to the boundary by dislocation pinning.

The problem of helium embrittlement has come to the fore with the advent of the fast breeder reactors which operate at high temperatures of the order of 500 to $700^{\circ} \mathrm{C}$ at which grain boundary sliding becomes predominant in the structural materials. The most important material of application in fast breeder reactors is stainless steels and most of the data on the phenomenon of helium embrittlement have been generated on this class of materials. In stainless steels helium is generated from the $\mathrm{B}^{10}(n, \alpha) \mathrm{Li}^{7}$ reaction which has a high thermal neutron cross-section or from $(n, \alpha)$ reactions between fast neutrons and elements present in the steels like nickel, chromium, nitrogen and iron. Most of the helium produced is heterogeneously distributed in the microstructure due to boron segregation and carbon replacement in $\mathrm{MC}$ and $\mathrm{M}_{23} \mathrm{C}_{6}$ precipitates. It is the segregation of helium at the grain boundaries that is the deciding factor in promoting helium embrittlement. The phenomenon of helium embrittlement in austenitic stainless teels is illustrated in figure 7 (Harries 1979) which shows the effects of fast reactor irradiaion on the tensile properties of solution-annealed 316 

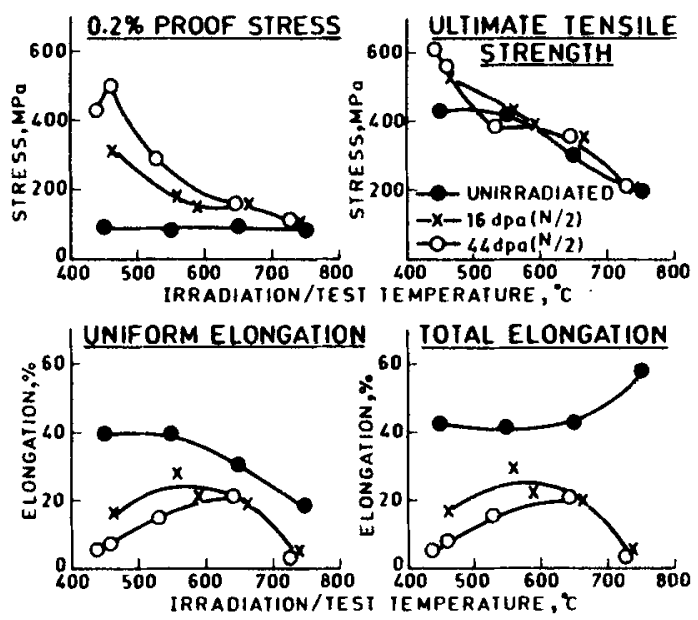

Figure 7. Effects of fast reactor irradiation on the tensile properties of solution annealed 316 stainless steel (Harries 1979).

stainless steel in the temperature range 400 to $750^{\circ} \mathrm{C}$. The effects of irradiation on the $0.2 \%$ yield stress, ultimate tensile strength, uniform elongation and total elongation are given in this figure. In the temperature range $400-650^{\circ} \mathrm{C}$, the yield strength increases with increase in dose; however the ultimate tensile strength is not significantly changed by irradiation. The ductilities, both uniform elongation and total elongations, are found to be significantly reduced by irradiation and the decrease in ductility increases with increasing dose. However, two distinct temperature regions and effects on ductilities can be discerned from these results. Upto $650^{\circ} \mathrm{C}$ where irradiation hardening is prevalent as seen from the effects on yield strength, the ductility reduction has been caused by the phenomenon of dislocation channelling which has already been discussed in the previous section. Above $650^{\circ} \mathrm{C}$ both uniform elongation and total elongation show a drastic reduction reaching almost negligible values at temperatures above $700^{\circ} \mathrm{C}$. This high temperature irradiation embrittlement is associated with increased tendency for fracture to occur along the grain boundaries and is a result of the production of helium and the stabilisation of cavities and wedge cracks by helium. The fracture mode in the unirradiated material which is mixed trans-and inter-granular changes to entirely inter-granular in the irradiated specimens.

The mechanisms for helium embrittlement have been critically reviewed by Bement (1972) and Harries (1979). Many of the fundamental features of helium embrittlement are well understood and corrective actions can be arrived at. Among these are grain size refinement (Harries and Roberts 1967), alloy adjustment to form precipitates within grains for trapping helium (Bloom and Weir 1967), improved melting practice to reduce concentrations of boron and other neutronic helium formers (Standring et al 1967), thermomechanical treatments to strengthen boundaries and adjacent zones (Levy and Wheeler 1967; Bhanu Sankara Rao et al 1981) and heat treatments for structural stabilisation against recovery or recrystallisation during irradiation (Nagasaki and Kawasaki 1969). 


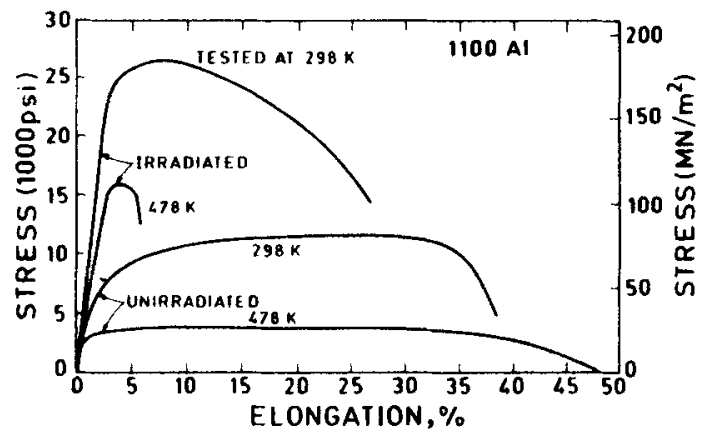

Figure 8. Effect of neutron irradiation (fluence $2.7 \times 10^{22} \mathrm{n.cm}-2$ at $323 \mathrm{~K}$ ) on the tensile curves of $1100 \mathrm{Al}$ at 298 and $478 \mathrm{~K}$ (Farrell and King 1973).

\subsection{Embrittlement due to other transmutation products}

It is possible that the mechanical properties of structural materials can be altered by transmutation products other than helium as well. One known example is the case of aluminium (Farrell and King 1973) in which neutron irradiation damage when irradiated to high fluences at about $323 \mathrm{~K}$ was found to consist of the fine precipitate of transmutation produced silicon and the associated dislocation network and very few voids. These defects were responsible for the large increase in the mechanical strength of commercial purity aluminium as shown in figure 8 . When tested at $298 \mathrm{~K}$ significant ductility loss was observed in this material which has been attributed to the production of embrittling silicon coming from the nuclear reaction,

$$
{ }^{27} \mathrm{Al}(n, \gamma) \rightarrow{ }^{28} \mathrm{Al} \rightarrow{ }^{28} \mathrm{Si}+\beta^{-} \text {. }
$$

Total elongation which was of the order of $38 \%$ in the unirradiated condition at $298 \mathrm{~K}$ came down to about 27 after irradiation. More important is the reduction in the uniform elongation which reduces from about $32 \%$ to about $7 \%$. It is also seen that the reductions in ductility at a higher temperature of $478 \mathrm{~K}$ are more severe with the total elongation decreasing from $\sim 48 \%$ to about $6 \%$ after irradiation and the uniform elongation becoming as low as about $3 \%$. This embrittlement at the higher temperature of $478 \mathrm{~K}$ has been shown to be due to the phenomenon of grain boundary embrittlement by helium which was discussed in $\S 3.3$. (In aluminium helium is produced from $(n, \alpha)$ reactions of $\mathrm{Li}$ and $\mathrm{B}$ present as impurities as well as from $\mathrm{Al}(n, \alpha)$ reactions).

\section{Irradiation creep}

Creep is the time-dependent deformation that a material undergoes at a constant stress and temperature. It is interesting to recall that the first radiation effect on the mechanical properties of metals to be reported was, that the creep rate of single crystals of cadmium increased on bombardment with alpha particles (Andrade 1945). Enhanced creep in a reactor environment was first observed in uranium in 1955 by Roberts and Cottrell (1956). The observed creep was explained on the basis of internal stresses developed by the neighbouring crystals undergoing anisotropic irradiation growth (see $\$ 5$ ). With regard to irradiation creep observed in isotropic materials the 
original thinking was that the normal thermal creep mechanism of dislocation climbcontrolled glide gets enhanced by the large concentration of vacancies produced by irradiation. Based on this, it was postulated (see for example, Rodriguez 1973) that at low temperatures below approximately $0.3 T_{m}$ where dislocation glide is the ratecontrolling mechanism there will be a reduction in creep rate under irradiation arising from irradiation hardening due to the defect clusters. At higher temperatures irradiation will increase the creep rate since climb-controlled glide is the creep mechanism and this can be assisted by the excess concentration of vacancies. One effect of the increased concentration of vacancies due to irradiation is to bring down the temperature range at which creep due to dislocation climb can occur. It was also realised that at very high temperatures $\sim 0.6$ to $0.7 T_{m}$ where the concentration of vacancies produced by irradiation is small compared to the thermal equilibrium concentration of vacancies itself, irradiation will not have any significant effect on creep and thermal creep would predominate. Now it is recognised that in addition to enhancement of climb and development of internal stress due to anisotropic growth, there can be new mechanisms of irradiation creep. For example, the mechanisms of stress-induced loop nucleation or loop alignment of interstitial clusters (SIPN) (Hesketh 1962) of stress-induced preferential absorption (SIPA) of interstitials at dislocations (Heald and Speight 1974; Wolfer and Ashkin 1975) have as a common feature that the formation or growth of interstitial loops and absorption of defects at the existing dislocations depend upon their orientation with respect to the external stress and therefore cause a macroscopic creep strain. Mansur (1979) has introduced the idea of the stress-induced preferential absorption and emission of radiation-generated defects into the climb-glide model and this has been called PAG creep. Indeed though the experimental results on irradiation creep have been limited there have been numerous mechanisms proposed to account for the phenomenon. Excellent reviews and summaries on the theories and mechanisms of irradiation creep are available (Gilbert 1971; Gilbert et al 1977; Bement 1972; Ehrlich 1981; Mansur and Reiley 1980). Most of the experimental results on irradiation creep have been generated on austenitic stainless steels and zirconium alloys, the two major core component materials in fast and thermal reactors respectively. In the following we present some of the typical results on these two groups of materials.

\subsection{Irradiation creep in stainless steels}

Irradiation creep results from pressurised tubes of $20 \%$ cold worked 316 stainless steel irradiated in EBR II are presented in figure 9 (Gilbert et al 1977). The creep strains (nominal hoop strain) that have been accumulated in the material after irradiation for $4138 \mathrm{~h}$ to a dose of $15 \mathrm{dpa}$ (displacements per atom) at hoop stresses of $34,69,138$ and $207 \mathrm{MPa}$ are shown in the figure for the temperature range $370-620^{\circ} \mathrm{C}$. The thermal creep lines represent creep data obtained from pressurised tubes which were aged in a furnace for the same time that the irradiation specimens were irradiated. In general, for a constant stress, the creep rate is dominated by irradiation creep processes at low temperatures and eventually swamped out by normal thermal creep at high temperatures. There is a mild temperature dependence for the irradiation creep process. Irradiation creep is increased by a factor of approximately 2.5 as the irradiation temperature is increased from 400 to $575^{\circ} \mathrm{C}$. Figure 10 is an example of the evidence which has been obtained to date to support the contention that irradiation creep is 


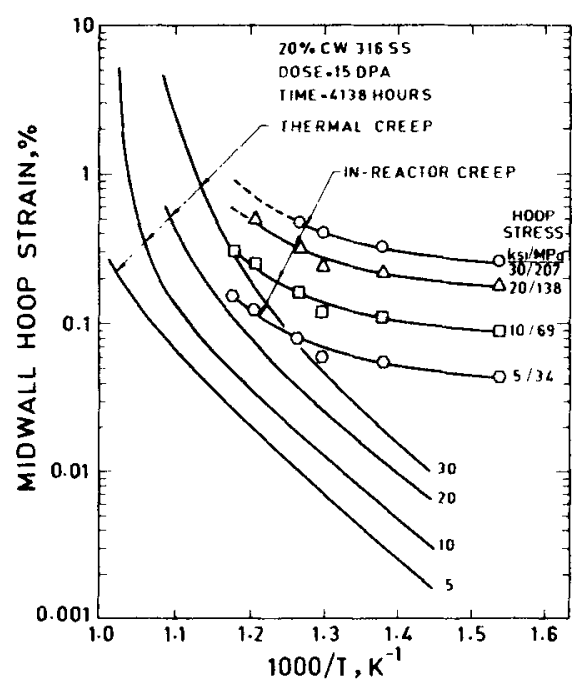

Figure 9. Irradiation creep results from pressurised tube of $20 \%$ coldworked 316 stainless steel (Gilbert et al 1977).

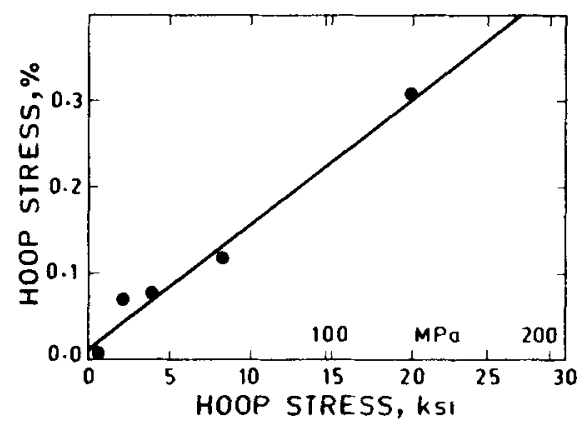

Figure 10. Linear stress dependence of irradiation creep in 316 stainless steel at $520^{\circ} \mathrm{C}$ and a fluence of 3 $\times 10^{22}$ n.cm ${ }^{-2}$.

linear in stress (these data were also obtained from pressurised tubes). Indeed it is this linear dependence in stress that distinguishes irradiation creep from the thermal creep for which the stress dependence has an exponent of 3 to 5 .

\subsection{Irradiation creep in zirconium alloys}

The various reactor structural components that are made out of zirconium alloys operate at a temperature below $300^{\circ} \mathrm{C}$, which is low relative to the melting point $\left(1800^{\circ} \mathrm{C}\right)$ and at an operating stress which is below one half of the yield stress (except for fuel clads). Thus one would expect the creep deformation to be insignificant. However, in reactor creep tests have demonstrated that neutron irradiation substantially increases the creep rate of zirconium alloys by a factor of upto 10 times (Fidleris and Williams 1966). Subsequently it became known that irradiation creep in zirconium alloys is anisotropic (Fidleris 1978). Thus efforts were made to correlate the observed irradiation creep data with several parameters such as crystallographic texture, coldwork, grain size and microstructure. Effect of neutron flux, dose, temperature and stress on the irradiation creep behaviour was also taken into account in explaining the inreactor creep behaviour of zirconium alloys. An excellent review on this subject has been contributed by Hurst et al (1976). 
A knowledge of out-of-pile thermal creep of zircaloys is necessary to have a better understanding of irradiation creep. Much of the early work was aimed at determining the effect of cold-work on the creep properties of zircaloy-2. Zirconium alloys in the annealed condition have shown more primary creep and also a higher secondary.creep rate, upto about 10,000 hours. At larger times, it has subsequently been shown that at low stresses, within the temperature range of $300-400^{\circ} \mathrm{C}$, cold work has little effect on the secondary creep rate (Van Echo and Poremka 1965). For sheet samples, Shober (1957) has shown that creep properties in both the longitudinal and transverse directions were virtually identical, which is strange for a notoriously anisotropic material like zircaloy-2. However, later studies by Bell (1962) have shown that at low stresses and at a temperature of $300^{\circ} \mathrm{C}$, the creep rate of specimens taken transversely from a tube is somewhat lower than that of longitudinal specimens. This difference has been attributed to a greater proportion of grains being available for slip in longitudinal specimens, assuming that most slip occurs on the $(10 \overline{10})$ prism planes in the $\langle 11 \overline{2} 0\rangle$ directions. Bell also showed that the creep rate generally decreases with time, ruling out self-diffusion as a major creep mechanism at this temperature. As such, it has proved difficult to produce a simple creep equation to include the variables of temperature and stress to predict the creep behaviour of zircaloy-2.

Fidleris and Williams (1966) were the first to show the significant increase in the creep rate due to irradiation. A typical curve showing the accelerated effect of irradiation on the creep rate is shown in figure 11. There is a general agreement that at flux levels of the order of $10^{13} \mathrm{n} / \mathrm{cm}^{2} / \mathrm{sec}$, the creep rate is directly proportional to flux. It takes a total dose of about $1 \times 10^{20} \mathrm{n} / \mathrm{cm}^{2}$ to reach the steady state creep. The steady state creep showed an increase with increasing temperature. However, as the creep rate is dependent on the stress level and flux, it is not possible to extrapolate the creep data obtained at one temperature, to describe the behaviour at some other temperature.

At temperatures around $300^{\circ} \mathrm{C}$, it has been found that the effect of stress on the creep rate is dependent on the absolute stress level. However, it is likely that the effect of stress on creep rate may be a complex one so that any extrapolation to stress levels beyond the limit of the test data may be unreliable.

Fabrication procedures affect the texture, grain shape and dislocation structure of zirconium alloy tubes. Thus different manufacturing procedures can produce tubes with different dimensional behaviours. Pressure tubes are normally manufactured by extrusion and cold drawing processes. Increased extrusion ratio leads to increased basal pole densities in the tangential direction $\left(F_{t}\right)$. Subsequent drawing or pilgering

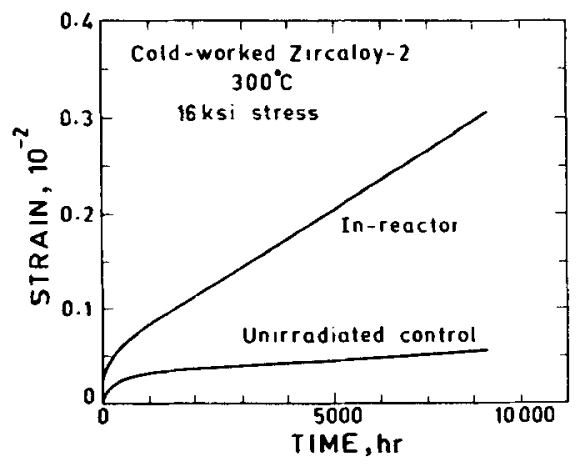

Figure 11. Accelerated in-reactor creep in zircaloy-2 (Watkins and Wood 1969). 
operations tend to rotate the basal poles into the radial direction $\left(F_{r}\right)$. The density of basal poles in the axial direction is almost zero.

Dimensional data are now available for cold-worked zircaloy pressure tubes manufactured by eight different routes and irradiated in the Hanford N Reactor, CANDU reactors at Pickering and Douglas Point and the Winfrith SGHWR. These data show that it would be desirable to have a higher $F_{t}$ (achieved by a high extrusion ratio) which would give a higher creep strength in the transverse directions. However, too high an $F_{t}$ value may also pose a practical problem from length increase considerations.

Holt (1979) has shown that there is only a weak dependence of creep on dislocation density. This is in agreement with the stress relaxation tests on extruded and coldworked $\mathrm{Zr}-2.5 \mathrm{wt} \% \mathrm{Nb}$ (Coleman et al 1975). The excellent correlation of the model developed by Holt and Ibrahim (1979) and the pressure tube data obtained by Holt (1979) show that the underlying physical assumption of Holt and Ibrahim (1979) namely that the strain producing mechanism for irradiation creep is glide, predominantly of $b=1 / 3\langle 1 \overline{1} 20\rangle$ dislocations on (1010) planes, but with some contribution from another type of glide, probably of dislocations with $b=1 / 3\langle 11 \overline{2} 0\rangle$ on $(0002)$ planes. Thus the creep strains can be related to crystallographic texture by a model based on variations in the amount of cross-slip of dislocations of the type $1 / 3<11 \overline{2} 0>$ from prism to basal planes. Such an attempt has recently been made by Causey (1981).

\section{Irradiation growth}

Irradiation growth is defined as a change in dimensions during irradiation in the absence of any applied stress; dimensional change under zero stress distinguishes "growth" from 'creep' which occurs under a stress. Irradiation growth occurs in single crystals and textured polycrystals of anisotropic metals and alloys by the unequal distribution of interstitial and vacancy loops on different crystallographic planes. In the following we shall present the results and models available for the phenomena in zirconium alloys (HCP structure) used for core components in thermal reactors and in metallic uranium (orthorhombic) used as a fuel in research reactors.

\subsection{Irradiation growth in zirconium alloys}

Irradiation growth occurs in all zirconium alloys and is anisotropic. It is known to depend on the crystallographic texture and substructure of the material (Fidleris 1975; Adamson 1977; Holt and Ibrahim 1979; Murgatroyd and Rogerson 1979). In general, irradiation growth is assumed to be a constant volume process, although the hypothesis of a volume change during growth has also been proposed (Dollins 1975) and recently small changes in density in zircaloy have been observed after irradiation (Harbottle and Herbillon 1980).

For fluences above about $1 \times 10^{25} \mathrm{n} \cdot \mathrm{m}^{-2}(E>1 \mathrm{MeV})$, growth strains were shown to increase with irradiation temperature upto about $573 \mathrm{~K}$ but were observed to decrease at higher temperatures.

Available data clearly indicate strong differences in the magnitude of irradiation growth for recrystallized and coldworked/stress-relieved zircaloy. The mechanisms of growth are also thought to be substantially different for these two metallurgical conditions (Fainstein-Pedraza et al 1978; Northwood 1977). 
Adamson et al (1981) have shown that the growth strains for both annealed and $20 \%$ cold-worked zircaloy exhibited a strong dependence on irradiation temperature (in the range of 644-723 K), upto fluences between $1.46 .3 \times 10^{25} \mathrm{n} . \mathrm{m}^{-2}$. The rate of increase in growth with temperature in the annealed longitudinal material was found to be higher than the rate in $20 \%$ cold-worked material. In general the growth behaviours in these two cases were similar suggesting a common mechanism of growth operating in both types of material at the applicable damage rates and irradiation temperatures.

Growth strains in a given direction in zircaloy are determined by the crystallographic texture i.e. proportional to $\left(1-f_{d}^{c}\right)$ where $f_{d}^{c}$ is the fraction of basal poles, $f^{c}$, in the direction $d$.

It appears that the high growth strains in annealed zircaloy are governed by the formation of dislocation arrays which then climb. This is a change in growth mechanism from that applying at lower irradiation temperatures and is similar to the mechanism for cold-worked materials. Thus irradiation growth is dependent not only on texture but also on dislocation density as reported by Holt (1979).

\subsection{Irradiation growth in metallic uranium fuel}

The dimensional instability of alpha uranium under reactor irradiation is one of the earliest known forms of radiation damage. During irradiation below about $500^{\circ} \mathrm{C}$, a single crystal of uranium extends in $\langle 010\rangle$ direction, and contracts in the $\langle 100\rangle$ direction. There is no noticeable extension or contraction in the $\langle 001\rangle$ direction. There is no change in the volume of the material. Polycrystalline uranium with a preferred orientation thus changes its shape during irradiation. It has been proposed that this "growth" results from the large number of vacancies and interstitials created by the passage of a fission fragment through the crystal. Above about $500^{\circ} \mathrm{C}$, self-diffusion is sufficiently rapid for these point defects to be annihilated, but at lower temperatures they aggregate into flat mono-layer plates which can be observed by transmission electron microscopy (Hudson et al 1962). Stresses due to anisotropic thermal expansion in the fission spike force, the vacancies and interstitials to aggregate on different crystal planes (Buckley 1962). Elongation, which is due to interstitial clusters, is therefore in the direction of minimum thermal expansion, $\langle 010\rangle$, and contraction, which is due to collapsed vacancy clusters, is in the direction of maximum thermal expansion, $\langle 100\rangle$. This correlation of the direction of irradiation growth with the direction of minimum thermal expansion has been observed in other anisotropic lattices also (Buckley 1962). This mechanism suggests no simple way to eliminate the basic growth process and the remedy for changes in shape is sought in producing uranium of small grain size and total preferred orientation. However, grains in uranium are notoriously imperfect and become more so during irradiation. Thus the presence of sub-boundaries may easily mask the effect of the nominal grain size.

Irradiation swelling is another phenomenon which takes place in metallic uranium fuel. There is a net volume increase due chiefly to the gaseous fission products xenon and krypton which at reactor operating temperatures tend to precipitate to form gas bubbles. The inert gases are extremely insoluble in solids and precipitate to form embryo gas bubbles on any suitable nuclei, e.g. dislocations, grain boundaries and twin boundaries. There is the additional possibility that the gas nucleates 'homogeneously'.

Since swelling is least when the gas pressure is high, i.e. when the bubbles are small, swelling would be reduced by increasing the number of heterogeneous nuclei if there 
was no subsequent coarsening. The gas bubbles can grow only when vacancies are available and these are plentiful above about $450^{\circ} \mathrm{C}$. However, the limitation to bubble growth will be the ability of the gas to redistribute within the metal.

Grain boundaries like dislocations, will tend to adhere to gas bubbles because this lowers the total surface energy. A moving grain boundary will also tend to drag the bubbles and owing to the greater binding force, the grain boundary will be able to drag very much larger bubbles than a dislocation. Hence if recrystallisation or grain growth occurs, small bubbles in the matrix will be swept and will undergo rapid coalescence. Thus if the number of gas bubbles is kept to a maximum, swelling will be minimum, by preventing their migration.

It has been found that minor alloying additions and impurities play a significant role in reducing swelling. Carbon, which is present in most commercial uranium in amounts of $300-1000 \mathrm{ppm}$, has a marked effect in reducing volume increases (Loomis and Pracht 1962). The greatest individual effect in reducing swelling was produced by $400-1200 \mathrm{ppm}$ of aluminium, which was further enhanced by the presence of about $300 \mathrm{ppm}$ of iron and $600 \mathrm{ppm}$ of carbon (Bellamy 1962; Pugh 1961). For producing this effect, however, it is necessary to quench the uranium from the beta phase and subsequently anneal it in the alpha phase. Uranium of this composition and heat treatment has been developed by UKAEA and is known as adjusted uranium and is known to have minimal irradiation growth effects.

\section{Void swelling}

In 1966 while carrying out electron microscopic examination of specimens of stainless steel irradiated in the Dounreay fast reactor (DFR) Cawthorne and Fulton (1967) found small spherical cavities in the material which seemed to contain nothing except a small amount of gas. In addition to being a new and curious scientific discovery, it was very soon appreciated that the development of void in a material meant that the density of the material would decrease and its physical size would increase and this can have very significant implications to the design of a fast reactor core. In the last 17 years the subject of void swelling has received intensive research leading to a physical understanding and quantifying of the phenomenon (Norris 1972; Johnston ei al 1976; Ehrlich 1981; Mansur 1982; Bates and Powell 1981).

Volumetric swelling caused by void formation has become a generally observed phenomenon for metals and alloys after neutron irradiation or heavy ion bombardment in the temperature range 0.30 to $0.60 T_{m}$. The basic ideas behind the formation of void as an irradiation produced defect have already been described in $\S 2$. The primary defects produced by irradiation are vacancies and interstitials and void formation occur only at temperatures higher than $0.30 T_{m}$ where both vacancies and interstitials are mobile. Void growth requires specifically three conditions: firstly that there is a supersaturation of vacancies; secondly the vacancies migrate to voids before being annihilated by interstitials and thirdly that more vacancies than interstitials arrive at void nuclei. The last condition is satisfied by the fact that other defects like dislocations have a bias for interstitials and absorb more interstitials than vacancies. The second condition is met if the temperature is high enough for vacancy mobility. The first condition is met when the temperature is low enough for the thermal equilibrium concentration of vacancies to be significantly lower than irradiation-induced concen- 
tration. Thus void formation occurs in a limited temperature range, of 0.3 to $0.6 T_{m}$.

Although there are important differences in detail the general nature of void formation for a variety of metals and alloys is similar. The voids are usually polyhedral and in FCC metals commonly take the shape of a truncated octahedron bounded by 6 square [001] faces and 8 hexagonal [111] faces (Bement 1972). Void shapes can vary and can be irregular however depending upon temperature and purity (Stiegler et al 1969). Faulted interstitial loops are also generally observed in metals and alloys having a low stacking fault energy (prismatic loops for high stacking fault energy) and together with the voids account for a population balance between interstitials and vacancies generated by neutron irradiation. Visible voids in stainless steels range in diameter from about 5 to $35 \mathrm{~nm}$ with the greatest number sized about $20 \mathrm{~nm}$. Void formation data for several high purity metals and alloys of different crystal structures are summarised in tables 4 and 5 (Bement 1972). Reference to the tables reveals that voids have been observed in FCC (Ni, Al, Cu, Pt), BCC (Mo, Fe, B, Nb, W) and HCP (Re) metals within the irradiation temperature range 0.3 to $0.6 T_{m}$. Zirconium and titanium are notable exceptions in that they exhibit large vacancy loops and a general absence of voids to a fluence of $3 \times 10^{21} \mathrm{n} / \mathrm{cm}^{2}$ (Brimhall et al 1971).

Most of the data on void swelling available are on austenitic stainless steels and nickel-base alloys because of their immediate interest as core component materials in fast reactors. Also much of the progress towards evaluating and controlling void swelling has been made possible by the use of charged particle bombardments in accelerators to rapidly simulate the damage that occurs in a reactor. However, the damage produced by heavy ion bambardment in accelerators could give results different from actual in-reactor irradiation. One major difference is that because of the higher dose rate and the larger rate of defects production by ion bombardment the peak temperature of swelling gets shifted to a higher temperature. For austenitic stainless steels this shift is about $150^{\prime \prime} \mathrm{C}$ (Johnston et al 1976) as illustrated in figure 12. (To quantify damage produced by ion irradiation the damage dose is calculated or represented as the number of times a lattice atom is displaced: displacements per atom or dpa). It has also been demonstrated that prior implantation of helium with an alpha particle beam is necessary when heavy ion irradiation is carried out to simulate the role

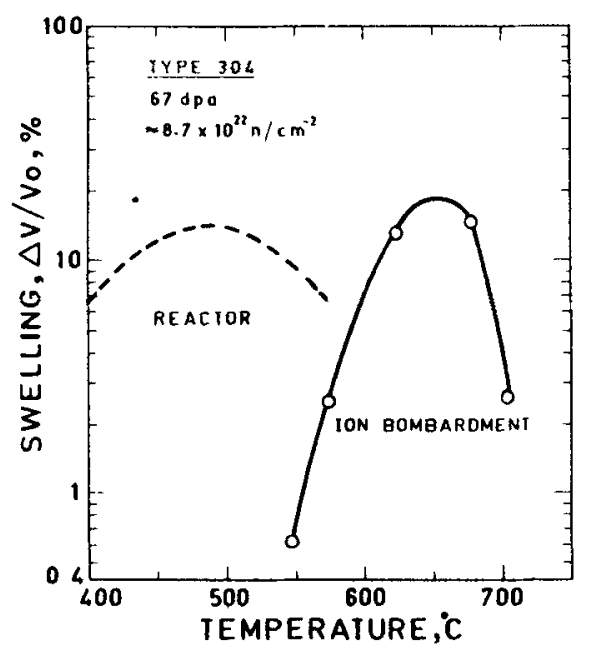

Figure 12. Temperature dependence of swelling in 304 stainless steel during reactor and ion irradiations (Johnston et al 1976). 


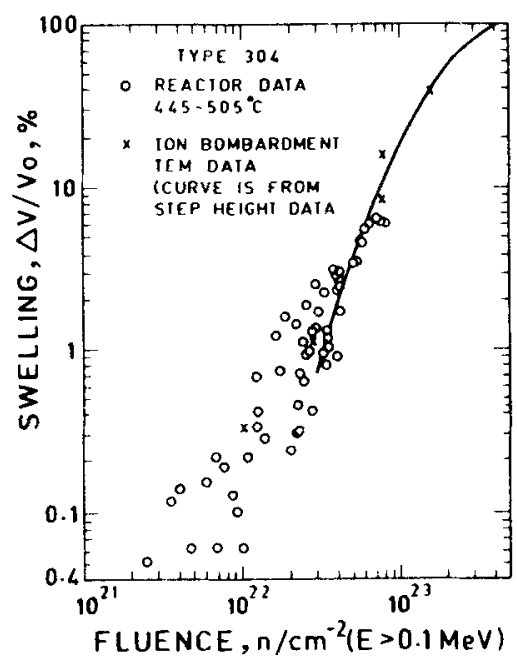

Figure 13. Dose dependence of swelling in 304 stainless steel by reactor and ion irradiation at the respective peak swelling temperatures (Johnston et al 1976).

of helium in stabilising voids in reactor irradiation. However, a good correlation can be obtained between swelling and fluence in reactor and ion irradiations when the swelling data at the respective peak swelling temperatures are compared as illustrated in figure 13 (Johnston et al 1976) where the swelling $v$ s fluence data for $t$ wo types of irradiation are shown and the ion dose has been converted to fluence by taking $10^{23} \mathrm{n} / \mathrm{cm}^{2}$ as equivalent to $77 \mathrm{dpa}$. The main point that emerges from the accelerated test using ion bombardment is that at the fluences of 2 to $3 \times 10^{23} \mathrm{n} / \mathrm{cm}^{2}$ which is the target fluence for commercial fast reactors, the swelling can be as large as 20 to $30 \%$. It may be seen from figure 13 that there is a threshold fluence below which no appreciable swelling occurs. The value of the threshold fluence is of the order of $10^{21} \mathrm{n} / \mathrm{cm}^{2}$, which corresponds to a value of approximately $6 \mathrm{dpa}$.

Swelling rates as a function of irradiation temperatures for M316, M316L, FV 548 and Nimonic PE 16 alloy irradiated in DFR to fast fluences up to $8.7 \times 10^{22} \mathrm{n} / \mathrm{cm}^{2}$ in the temperature range $300-650^{\circ} \mathrm{C}$ are shown in figure 14 (Bramman et al 1971). The swelling rate in $\mathrm{M} 316 \mathrm{~L}$ is only half that in M316. Also peak swelling rates are observed at different temperatures. M316 shows peak swelling rate at $600^{\circ} \mathrm{C}$ while in the case of the lower carbon $\mathrm{M} 316 \mathrm{~L}$, peak swelling occurs around $500^{\circ} \mathrm{C}$. The peak swelling in $\mathrm{M} 316$ at $600 \mathrm{C}$ is associated with the precipitation of $\mathrm{M}_{23} \mathrm{C}_{6}$ carbides in this temperature range. These results suggest that control of carbon level is important in determining void swelling. For both M316 and 316 L cold work is found to drastically reduce the swelling rate. It has been shown that with a very high initial dislocation density in the cold worked condition the nucleation of both interstitial dislocation loops and voids is inhibited as a consequence of dominance of point defect recombination at the dislocation sinks (Little et al 1980). FV 548 in both solution annealed and cold-worked conditions shows lower swelling rates than M316. FV 548 contains higher carbon level $(0.06$ to $0.09 \%)$ than M316 $(0.05 \%)$ but has a niobium level which is specified as 8 times the carbon content. This suggests that inhibition of intergranular $\mathrm{M}_{23} \mathrm{C}_{6}$ precipitate by the addition of $\mathrm{MC}$ carbide forming elements is effective in reducing void swelling. The beneficial effect of carbide stabilising elements such as titanium or niobium in reducing void swelling has been demonstrated by many studies (Bloom and Stiegler 1970; Ehrlich and Gross 1974). Figure 13 also shows that 

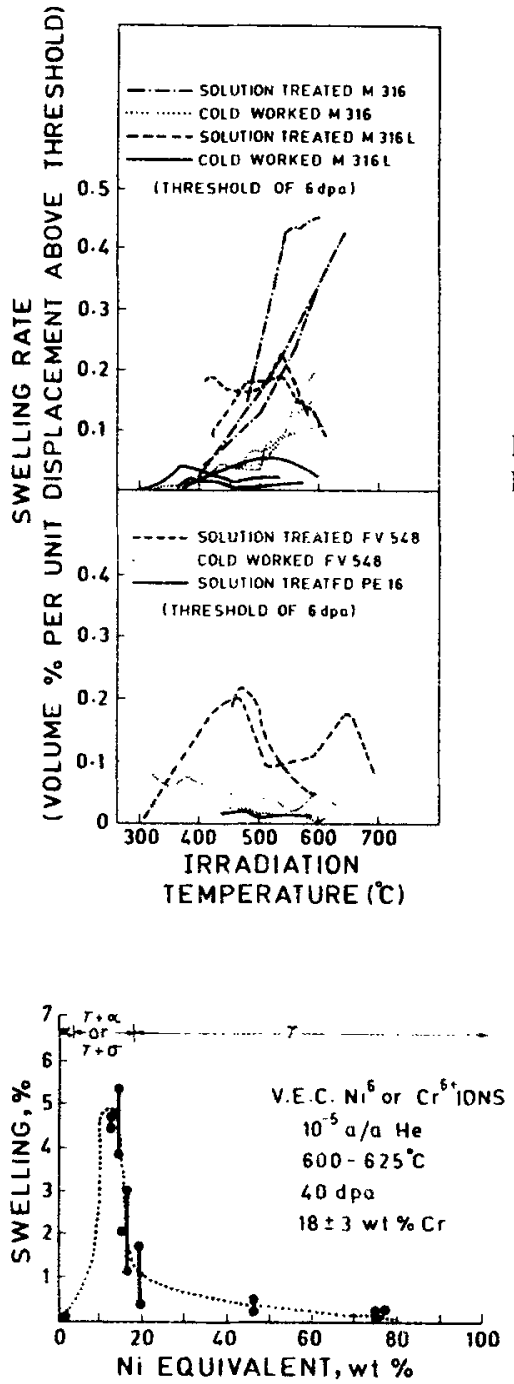

Figure 14. Swelling rates in M316, M316L, FV548 and PE16 alloys (Bramman et al 1971).

Figure 15. Void swelling in steels and nickelbase alloys as a function of nickel equivalent (Harries 1974).

Nimonic alloy PE 16 has a very low swelling rate relatively insensitive to irradiation temperature compared to stainless steels.

The void swelling in various steels and nickel-base alloys, as a function of nickel equivalent contents, is shown in figure 15 (Harries 1974). The void swelling is virtually zero for the ferritic steel (approximately $2 \%$ nickel equivalent), relatively high and variable for the austenitic stainless steels (3-18\% nickel equivalent) and decreases progressively at higher nickel contents. A similar dependence of void swelling in austenitic stainless steels and nickel-base alloys with nickel content has also been observed by other workers (Johnston et al 1976).

Nickel-base alloys like Nimonic PE 16, though attractive from the point of view of low swelling, have a greater tendency for helium embrittlement discussed in $\S 3.3$ because of the higher production of helium due to the nickel $(n, \alpha)$ reactions. Because of the very low swelling resistance of ferritic steels a number of ferritic/martensitic steels have come to the fore as candidate materials for core components for fast breeder 
reactors. Among these must be mentioned the HT9 and D57 two high strength ferritic steels, which are candidate materials for potential applications in the fast breeder reactor cores in the us (Chin et al 1982) and the FV 448 martensitic stainless steel being seriously considered and studied in the UK programme (Little et al 1980). The mechanisms of swelling suppression in alpha iron and ferritic steels have been summarised by Little (1979) who has emphasised the key role played by both interstitial and substitutional solutes in inducing enhanced mutual recombination of point defects through trapping processes and also in lowering dislocation mobility and bias for preferential self-interstitial capture in these materials and thereby controlling their void swelling responsc. Based on careful transmission electron microscopic studies of specimens irradiated in a high voltage electron microscope Little et al (1980) have concluded that the suppression of void formation in the FV 448 martensitic stainless steel is to be attributed to the simultaneous formation of $a\langle 100\rangle$ interstitial dislocation loops in addition to the $a / 2\langle 111\rangle$ interstitial dislocation loops. Loops

Table 4. Voids in pure metals (Bement 1972)

\begin{tabular}{|c|c|c|c|}
\hline Metal & $\begin{array}{c}\text { Temperature } \\
\text { range voids } \\
\text { observed } \\
T, T_{m}\end{array}$ & $\begin{array}{c}\text { Minimum reported } \\
\text { fluence } \\
\left(\times 10^{19} \mathrm{n} / \mathrm{cm}^{2}\right)\end{array}$ & $\begin{array}{l}\text { Maximum reported } \\
\text { volume fraction } \\
\text { of voids } \\
(\%)\end{array}$ \\
\hline $\mathrm{Ni}-\mathrm{FCC}$ & $0.31-0.60$ & 0.11 & 0.64 \\
\hline Al-FCC & 0.35 & 3 & high \\
\hline $\mathrm{MO-BCC}$ & $0 \cdot 30-0-49$ & 3 & 0.28 \\
\hline Cu-fec & $0 \cdot 39$ & 12 & 0.17 \\
\hline Re-HCP & 0.390 .41 & 50 & 0.10 \\
\hline $\mathrm{Fe}-\mathrm{BCC}$ & $(0.40$ & 300 & 0.12 \\
\hline V-нсC & 0.300 .41 & 490 & 1.77 \\
\hline $\mathrm{Nb}-\mathrm{BCC}$ & $0.2 r_{r} 0.40$ & 2500 & - \\
\hline $\mathrm{ZT}-\mathrm{HCP}$ & $(j \cdot 42$ & $\begin{array}{c}300 \\
\text { (voids not observed) }\end{array}$ & \\
\hline Ti-HCP & & $\begin{array}{l}300 \\
\text { (voids not observed) }\end{array}$ & \\
\hline
\end{tabular}

Table 5. Voids in alloys (Bement 1972)

\begin{tabular}{|c|c|c|c|c|}
\hline Alloys & & $\begin{array}{l}\text { Temperature } \\
\text { range voids } \\
\text { observed } \\
\left(T / T_{m}\right)\end{array}$ & $\begin{array}{l}\text { Minimum } \\
\text { reported } \\
\text { fluence } \\
\left(\times 10^{-19} \mathrm{n} / \mathrm{cm}^{2}\right)\end{array}$ & $\begin{array}{c}\text { Maximum } \\
\text { reported } \\
\text { volume } \\
\text { fraction } \\
\text { of voids } \\
(\%)\end{array}$ \\
\hline 304 ss (annealed) & & $0.38-0.55$ & 14 & $4 \cdot 1$ \\
\hline 316 ss (annealed) & & $0 \cdot 38-0.51$ & 500 & 3 \\
\hline 304 si (cold-worked) & $\mathrm{FCC}$ & 0.40 & 2800 & 0.1 \\
\hline 316 ss (cold-worked) & & $0.41-0.58$ & 2300 & 0.02 \\
\hline $\mathrm{V}-20^{\circ}, \mathrm{Ti}$ & $\mathrm{BCC}$ & & $\begin{array}{c}1400 \\
\text { (Voids not yet } \\
\text { observed) }\end{array}$ & \\
\hline
\end{tabular}


Table 6. Relative probabilities for the formation of $a\langle 100\rangle$ dislocation loops in a range of BCC metals (Little et al 1980)

\begin{tabular}{ll}
\hline Metal & $\begin{array}{c}\text { Relative } \\
\text { probabilities }\end{array}$ \\
\hline Nb & $4.3 \times 10^{-5}$ \\
V & $5.5 \times 10^{-5}$ \\
Fe & $5.7 \times 10^{-9}$ \\
Ta & $7.9 \times 10^{-11}$ \\
Mo & $1.9 \times 10^{-19}$ \\
W & $1.4 \times 10^{-27}$ \\
\hline
\end{tabular}

with $b=a / 2\langle 111\rangle$ are the predominant loop type nucleated. However there is a finite probability of about $5.7 \times 10^{-9}$ at $420^{\circ} \mathrm{C}$ for the nucleation of $a\langle 100\rangle$ loops. When both types of loops are present $a / 2<111\rangle$ network acts as a vacancy sink in the system and absorbs the net vacancy flux created by the growth by preferential interstitial capture of the isolated a 100 loops. This explanation seems to be quite reasonable since the tendency for void suppression or swelling resistance should be governed by the probability of $a\langle 100\rangle$ loop formation relative to that for $a / 2\langle 111\rangle$ loop formation. The values of this probability for the various BCC metals which include the technologically important metals such as niobium, molybdenum, tungsten, vanadium and tantalum are shown in table 6. It can be seen that relative to alpha $\mathrm{Fe}, \mathrm{V}$ and $\mathrm{Nb}$ are more favourable with respect to $a\langle 100\rangle$ loop formation while Mo, W and Ti are less favourable. Hence it may be inferred that $\mathrm{V}$ and $\mathrm{Nb}$ are likely to exhibit relatively high swelling resistance if irradiated in the cold-worked condition, whereas tantalum, molybdenum and tungsten would show higher susceptibility for void formation than iron and ferritic steels, the susceptibility increasing in the order tantalum, molybdenum, tungsten. The results cited earlier (tables 4 and 5) tend to support this explanation since molybdenum was found to show void formation whereas voids could not be observed in V-Ti alloy.

The role of major elements like nickel, in iron-chromium-nickel alloys, has been pointed out already. The swelling of iron-chromium-nickel alloys can be significantly reduced by one or two orders of magnitude by minor elements. It has already been pointed out that commercial stainless steels containing stabilisers such as titanium and niobium are found to swell less than the unstabilised stainless steels. Bloom et al (1976) have reported that the additions of silicon and titanium to type 316 steel cause an appreciable reduction in swelling. Bates (1975) investigated the effects of varying the minor element content in a type 316 stainless steel on in-reactor swelling (figures 16 and 17). Individual additions of many of the elements that are normally added to steels were made to a base alloy of $\mathrm{Fe}-15 \mathrm{Cr}-20 \mathrm{Ni}$. Only silicon, titanium, zirconium and niobium caused an appreciable reduction in swelling with zirconium being the most effective on a per atom basis. Boron, carbon, phosphorous molybdenum, manganese and aluminium either had little effect or caused a slight increase in swelling. These studies have confirmed the observation of Bloom et al (1976) that combination of silicon and titanium appears to be more effective in reducing swelling than the simple addition of the individual effects would suggest. The temperature dependence of swelling in the 


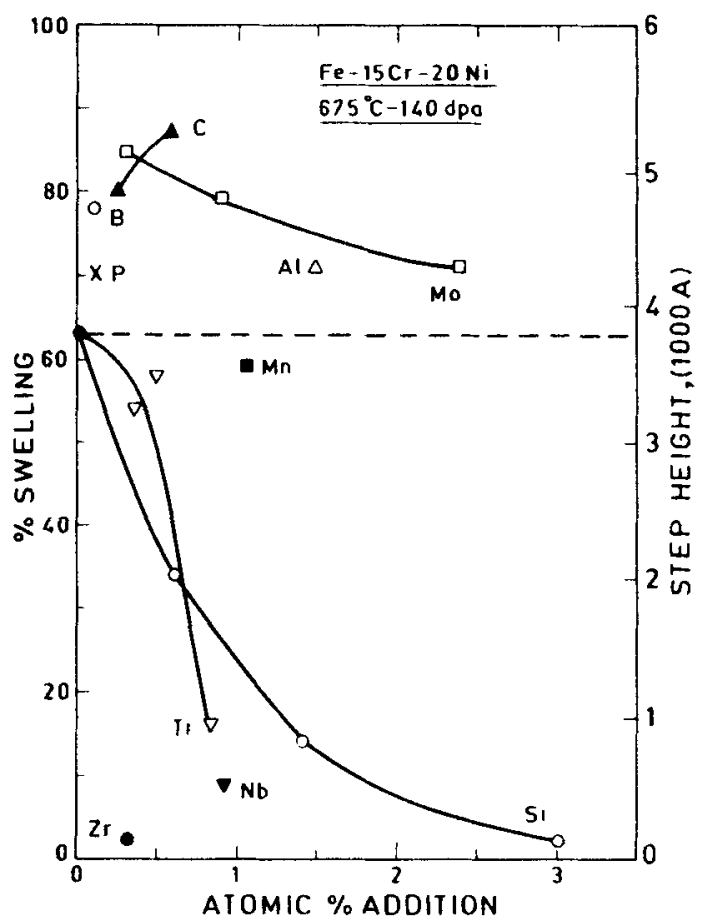

Figure 16. Effects of individual minor element additions on the swelling of $\mathrm{Fe}-15 \mathrm{Cr}-20 \mathrm{Ni}$ steel (Johnston et al 1976)

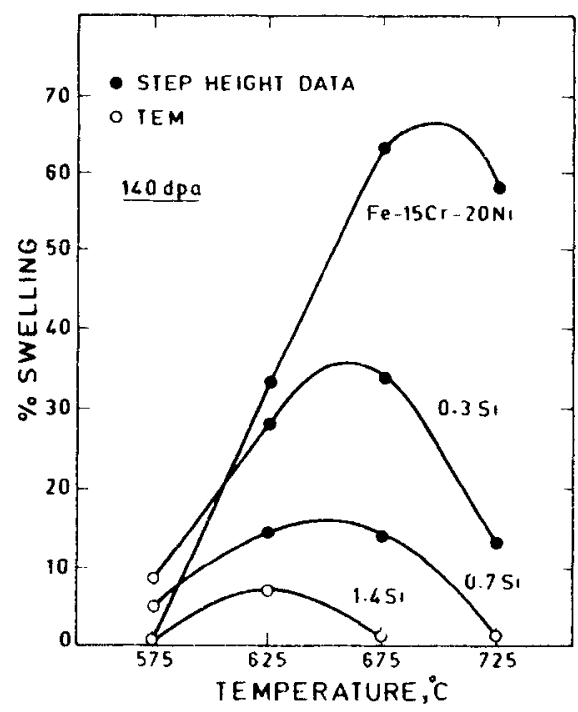

Figure 17. Effect of $\mathrm{Si}$ additions on swelling in $\mathrm{Fe}-15 \mathrm{Cr}-20 \mathrm{Ni}$ steel (Johnston et al 1976). 
Fe-15Cr-20Ni alloy with additions of silicon is shown in figure 16. The swelling suppression is greater at higher temperatures. Also there is a tendency to shift the peak swelling temperature towards a lower temperature region.

The phenomenon of void swelling has engineering implications for almost all the core components in a fast breeder reactor. It increases the diameter of the fuel pin which is considered to be partly beneficial since it helps to reduce fuel-clad mechanical interaction by making more room available inside the pin for the fuel to swell. However pin swelling could restrict coolant passages in the assembly leading to overheating as well as increasing the pumping power needed to maintain the coolant flow. While for the amount of swelling expected this may not be a serious problem for the fuel pin performance per se, difficulties may arise because of the differential swelling between the fuel pin, the wire wrap on the fuel pin or the grid supporting the pin and the hexagonal wrapper holding the assembly of fuel pins. The most serious effect of void swelling is on the subassembly wrapper. As void swelling depends on fluence and temperature the wrappers will elongate by different amounts depending on their exact position within the core. The wrapper is a long stiff structure which in most core locations is irradiated more on one side than the other. This causes the wrapper to bow so that its top end moves away from the core centre. This problem of subassembly bowing is important when the subassemblies are unrestrained, and one of the corrective measures is to alter the design by using the constrained core concept in which the bow of the subassemblies is accommodated by elastic and creep strains in the wrappers and deflection of wrappers between the support points. In fact, irradiation creep $(\S 5)$ which enhances deformation capability of the material during irradiation is used to alleviate the stresses developed due to swelling. Other solutions within the unrestrained core concept itself are operational and include periodic rotation of the subassemblies and the adoption of the use of wrapper materials resistant to void swelling. For the viable economics of the fast breeder reactor it is considered necessary that the clad and wrapper materials should have void swelling not exceeding $6 \%$ in the targeted burn-up. $20 \%$ cold-worked 316 type stainless steel with 0.4 to $0.6 \mathrm{wt} \%$ silicon and stabilised with titanium additions of 0.3 to $0.5 \mathrm{wt} \%$ is considered to meet this requirement and has been used in EBR II in USA and Superphenix in France and is the prime candidate material in our own programme for building fast breeder power reactors in the future.

\section{Summary}

A review of radiation effects in nuclear reactor materials has been niade; the irradiation effects have been correlated with the crystal structure of the materials. Five phenomena, irradiation hardening, irradiation embrittlement, irradiation creep, irradiation growth and void swelling that occur in materials by neutron irradiation in a reactor environment have been discussed. There is definitive evidence that in FCC and in basal slip HCP metals ( $\mathrm{Zn}, \mathrm{Cd}$ ), irradiation produced defects become rate-controlling in plastic deformation. In the case of BCC metals and prism slip нCP metals ( $\mathrm{Zr}, \mathrm{Ti}$ ) irradiation hardening appears to be athermal in nature. In all cases irradiation hardening is accompanied by irradiation embrittlement manifested by reduced work hardening and lowered ductility. This type of embrittlement caused by irradiation in normally ductile metals arises from localised deformation due to dislocation channeling. In the case of BCC metals and alloys which undergo ductile to brittle transition at low temperatures, 
irradiation shifts the transition temperature to higher temperatures and lowers the fracture energy in the ductile region (upper shelf energy at high temperatures). The ferritic steels chosen for pressure vessels and containment vesseis of reactor systems have $\mathrm{BCC}$ crystal structure and it is necessary to limit the residual elements and to have a fine grain size in these steels so that the ductile-brittle transition temperature and its shift after irradiation are minimised. Helium embrittlement becomes important at higher temperatures $>0.4 T_{m}$ where grain boundary slidings become predominant; formation of helium bubbles from $(n, \alpha)$ transmutations at grain boundaries promotes intergranular fracture by stabilising wedge cracks and grain boundary cavities. Embrittlement due to other transmutation products can also occur as exemplified by formation of $\mathrm{Si}$ in $\mathrm{Al}$. The influence of irradiation on creep depends on temperature. At low temperatures where irradiation hardening predominates creep rate is reduced. Irradiation-produced vacancies enhance climb and thereby lowers the temperature at which creep by climb-controlled glide can occur. In addition to such enhanced thermal creep, irradiation also causes creep due to new mechanisms which arise from stressinduced orientation/alignment of dislocation loops and stress-induced absorption of interstitials at dislocations. Irradiation growth (change in dimensions under zero stress) occurs in anisotrophic materials like $\mathrm{Zr}$ (HCP) and $\mathrm{U}$ (orthorhombic) by the unequal distribution of interstitials and vacancy loops on different crystallographic planes. Void swelling is a phenomenon that occurs at temperatures between 0.3 and $0.6 T_{m}$ and at large irradiation doses typical of fast reactors. HCP metals like $\mathrm{Zr}, \mathrm{Ti}$ and $\mathrm{BCC}$ refractory metals and ferritic/martensitic steels are less prone to void swelling than the austenitic stainless steels and nickel-base alloys. Nickel-base alloys have better void swelling than stainless steels but their greater susceptibility to helium embrittlement offsets this advantage. Stainless steels with controlled $\mathrm{Si}$ additions stabilised with $\mathrm{Ti} / \mathrm{Nb}$ cold worked to about $20 \%$ are found to have acceptable swelling rates for fast reactor applications.

\section{References}

Adamson R B 1977 in Zirconium in the nuclear industry (Philadelphia: American Society for Testing and Materials) ASTM STP 633, pp. 326

Adamson R B, Tucker R P and Fidleris V 1981 in Fifth International Conference on Zirconium in the Nuclear Industry (ed.) D. Franklin (Philadelphia: American Society for Testing and Materials) ASTM STP 754

Andrade E N 1945 Nature (London) 156119

Arsenault R J (ed.) 1973 Proc. Int. Conf. Defects and Defect Clusters in BCC Metals and their Alloys; Nucl. Metall. 18629

Arsenault R J 1976 in Treatise on materials science and technology. Vol. 6. Plastic deformation of materials (ed.) Herbert Herman (New York: Academic Press) pp. 83

Baldev Raj, Kasiviswanathan K V and Rodriguez P 1983 in Activity Report of Metallurgy Programme 1981 and 1982 (Kalpakkam: Reactor Research Centre) RRC-60, pp. 67

Bates J F 1975 in Properties of reactor structural alloys after neutron or particle irradiation (Philadelphia: American Society for Testing and Materials), ASTM STP 570 pp. 369

Bates J F and Powell R W $1981 \mathrm{~J}$. Nucl. Mater. 102200

Bell L G 1962 Report AECL 1456 (Chalk River: Atomic Energy of Canada Ltd.)

Bellamy R G 1962 Inst. of Metals Symposium on Uranium and Graphite, London

Bement A L 1972 Rev Roum Phys 17 505, 519, 607, 619

Bhanu Sankara Rao K, Seetharaman V, Mannan S L and Rodriguez P 1981 J. Nucl. Mater. 1027

Bloom E E and Stiegler J O 1970 J. Nucl. Mater. 35244

Bloom E E, Stiegler J O, Rowcliffe A F and Leitnaker J M 1976 Scripta. Met. 10303 
Bloom E E and Weir J R (Jr) 1967 in Irradiation effects in structural alloys for thermal and fast reactors (Philadelphia: American Society for Testing and Materials) ASTM STP 456 pp. 241

Bramman J I, Bagley K Q, Cawthorne C, Fulton E J and Sinclair W D J 1971 in Voids formed by irradiation of reactor materials Proc. BNES Conf. (eds) S F Pugh, M H Loretts and D I R Norris (London: British Nuclear Energy Society) pp. 27

Brenner S S, Wagner R and Spitznagel I A 1978 Metall. Trans. A9 1761

Brimhall J L, Kulcinski G L, Kissinger H E and Mastel B 1971 Rad. Eff. 9273

Buckley S N 1962 in Properties of reactor materials and the effects of radiation damage (ed.) D J Litter (London: Butterworths) pp. 413

Causey A R $1981 \mathrm{~J}$. Nucl. Mater. 98313

Cawthorne C \& Fulton E J 1967 Nature (London) 216575

Chin A B, Neuhold R J and Straalsund J L 1982 Nucl. Technol. 57426

Chow J G Y, McRickard S and Gruinsky D H 1969 in Radiation damage in solids (Vienna: International Atomic Energy Agency) Vol. 1, pp. 277

Coleman C E, Causey A R and Fidleris V 1975 Report AECL-5042 (Chalk River: Atomic Energy of Canada Ltd)

Diehl J 1970 in Vacancies and interstitials in metals (eds) A Seeger, D Schumacher, W Schilling and J Diehl (Amsterdam: North-Holland Co) pp. 739

Diehl J 1977 in Proc. Indo-German Seminar on Radiation Damage (Kalpakkam: Reactor Research Centre) pp. 336

Diehl J and Seidel G P 1969 in Radiation damage in reactor materials (Vienna: International Atomic Energy Agency) Vol. 1 pp. 209

Diehl J, Siedel G P and Weller M 1968 Suppl. Trans. Jpn Inst. Metals 9219

Dollins C C 1975 J. Nucl. Mater. 5961

Ehrlich K 1980 in Proc. Joint JEN-KFK Seminar on Materials for Reactor Vessels and Components, Paper No. 7, Madrid, November 1980

Ehrlich K 1981 J. Nucl. Mater. 100149

Ehrlich K and Gross R 1974 in Proc. Symp. on Fuel and Fuel Elements for Fast Reactors (Vienna: International Atomic Energy Agency) Vol. 2, p. 179

Evans A G and Rawlings R D 1969 Phys. Status Solidi 349

Fainstein-Pedraza D, Savino E J and Pedraza A J 1978 J. Nucl. Mater. 73151

Farrell K and King R T 1973 Metall. Trans. 41223

Fidleris V 1975 Atomic Energy Rev. 1361

Fidleris V 1978 Paper presented at Int. Conf. Reactor Materials Science, Alushta, USSR May 1978

Fidleris V and Williams C D 1966 Electrochem. Technol. 4258

Fleischer R L 1962 Acta Metall. 10835

Fleischer R L 1962 J. Appl. Phys. 333504

Gilbert E R 1971 Reactor Technol. 14258

Gilbert E R, Straalsund J L and Wire G L 1977 J. Nucl. Mater. 65266

Grant S P and Fortner E 1972 Metals Engg. Q. 1217

Hamad A M, Sharma B D and Rodriguez P 1975 Trans. Indian Inst. Metals 28231

Harbottle J E and Herbillon F 1980 J. Nucl. Mater. 90249

Harries D R $1979 \mathrm{~J}$. Nucl. Mater. 822

Harries D R and Roberts A C 1967 in Effects of radiation on structural materials (Philadelphia: American Society for Testing and Materials) ASTM STP 426, pp. 21

Heald P T and Speight M V 1974 Philos. Mag. 291075

Hesketh R V 1962 Philos. Mag. 71417

Holt R A 1979 J. Nucl. Mater. 82419

Holt R A and Ibrahim E F 1979 Acta Metall. 271319

Hudson B, Westmacott K H and Makin M J 1962 Philos. Mag. 7377

Hurst P, Nichols R W, Pickles B, Watkins B and Wood D S 1976 Atomic Energy Rev. 14439

Johnston W G, Lauritzen T, Rosolowski J H and Turakalo A M 1976 J. Metals 2819

Kayano H, Higashiguchi Y and Yagima S $1977 \mathrm{~J}$. Nucl. Sci. Technol. 14117

Kocks U F, Argon A S and Ashby M F 1975 Progress in Mater. Sci. 191

Koppenal T J 1965 Philos. Mag. 111257

Koppenal T J and Arsenault R J 1965 Philos. Mag. 12951

Koppenal T J and Arsenault R J 1971 Metall. Rev. 157175 
Levy I S and Wheeler K R 1967 in Effects of radiation on structural materials (Philadelphia: American Society for Testing and Materials) ASTM STP 426, pp. 458

Li J C M and Mukherji A K (eds) 1972 Proc. John E. Dorn Memorial Symposium on Rate Processes in Plastic Deformation (Metals Park OH: American Society for Metals)

Little E A 1967 Phys. Status Solidi A3 983

Little E A 1976 Int. Metals Rev. 2125

Little E A $1979 \mathrm{~J}$. Nucl. Mater. 8711

Little E A, Bullough R and Wood M H 1980 UKAEA Report AERE-R 9678 (Harwell: Atomic Energy Research Establishment)

Loomis B A and Pracht D W 1962 USAEC Report ANL-6532 (Argonne: Argonne National Laboratory)

Makin M J 1967 in Radiation effects (ed.) W F Sheely (New York: Gordon and Breach) pp. 627

Mansur L K 1979 Philos. Mag. A39 497

Mansur L and Bloom E E 1982 J. Metals 3423

Mansur L K and Reiley T C $1980 \mathrm{~J}$. Nucl. Mater. 9060

Matta M K, Batra I S and Sharma B D 1977 Trans. Indian Inst. Metals 30240

Murgatroyd R A and Rogerson A 1979 J. Nucl. Mater. 79302

Nagasaki S and Kawasaki S 1969 in Radiation damage in reactor material (Vienna: International Atomic Energy Agency) Vol. 2, pp. 161

Nichols R W and Cowan A 1971 Atomic Energy Rev. 91

Norris D I R 1972 Rad. Effects 141

Norris D I R 1972 Rad. Effects 151

Northwood D O 1977 Atomic Eneryy Rev. 15547

Ohr S M, Tucker R P and Wechsier M S 1968 Suppl. Trans. Jpn Inst. Metals 9187

Pugh S F 1961 J. Nucl. Mater. 4177

Roberts A C and Cottrell A H 1956 Philos. Mag. 1711

Rodriguez P 1973 in Radiation damage in reactor materials (Kalpakkam: Reactor Research Centre) RRC-1, pp. 135

Rodriguez P 1977 in Indo-German Seminar on Radiation Damage (Kalpakkam: Reactor Research Centre) pp. 353

Rodriguez. P and Dasgupta P 1972 in Recent developments in metallurgical science and technology (New Delhi: Indian Institute of Metals) pp. 47

Rogerson A and Murgatroyd R A 1979 J. Nucl. Mater. 80253

Seeger A 1958 Proc. Second Int. Conf. Peaceful U ses of Atomic Energy (New York: United Nations) 6250

Seidel G P 1969 Rad. Effects 1177

Shober F R 1957 Report BMI 1168 (Columbus: Battelle Memorial Institute)

Spitznagel J A, Shogan R P and Phillips J A 1976 in Irradiation effects on the microstructure and properties of materials (Philadelphia: American Society for Testing and Materials), ASTM STP 611, pp. 434

Standring J, Bell I P, Tickle H and Glendinning A 1967 in Irradiation effects in structural alloys for thermal and fast reactors (Philadelphia: American Society for Testing and Materials) ASTM STP 456, pp. 414

Steele L E 1975 Neutron irradiation embrittlement of reactor pressure vessel steels, technical report Series No. 163 (Vienna: International Atomic Energy Agency)

Stiegler J O, Farrell K, Dubose C K H and King R T 1969 in Radiation damage in reactor materials (Vienna: International Atomic Energy Agency) Vol. 2, pp. 229

Van Echo J A and Poremka S W 1965 Report BMI-X-10113 (Columbus: Battelle Memorial Institute)

Watkins B and Wood D S 1969 in Applications related phenomena in zirconium and its alloys (Philadelphia: American Society for Testing and Materials) ASTM STP 458, pp. 226

Wechsler M S 1967 Nucl. Safety 8461

Wechsler M S 1972 in Defects in refractory metals (eds) R de Batist et al (Mol, Belgium: Studiecentrum voor Kernenergie) pp. 235

Wechsler M S 1976 in Proc. Int. Conf. on Fundamental Aspects of Radiation Damage in Metals (eds) M T Robinson and F W Yong Jr, USERDA Report CONF 751006, Vol. 2, pp. 991

Wolfer W G and Ashkin M 1975 J. Appl. Phys. 46547 